\title{
UMA ANÁLISE DISCURSIVA DE EMENTAS DE PSICOPATOLOGIA EM CURSOS DE PSICOLOGIA
}

\author{
A DISCURSIVE ANALYSIS OF PSYCHOPATHOLOGY SUMMARIES \\ IN PSYCHOLOGY COURSES
}
UN ANÁLISIS DISCURSIVA DE EMENTAS DE PSICOPATOLOGÍA EN CURSOS DE PSICOLOGÍA

Conrado Neves Sathler ${ }^{1}$, Márcia Aparecida Amador Mascia ${ }^{2}$

\section{RESUMO}

Apresentamos os resultados parciais de uma pesquisa sobre o ensino de Psicopatologia em cursos brasileiros de Psicologia, tendo como corpus 5 (cinco) ementas, uma de cada região do país. Filiado aos estudos foucaultianos, o objetivo deste trabalho consiste em discutir as relações entre modos de produção de subjetividade, governamentalidade, biopolítica e disciplina. Os resultados apontam o ensino da Psicopatologia como dispositivo de (re)produção de subjetividades na Educação ligadas aos mecanismos de controle e administração de corpos e populações e indicam a necessidade de reavaliação do seu lugar frente às novas demandas postas pelas políticas públicas destacando o Sistema único de Saúde. Compreendemos que o objeto de estudo da disciplina, as relações discursivas presentes neste campo e as técnicas de intervenção fundamentam ações profissionais de consequências éticas significativas ao país e, por isso, requerem alterações próprias e articuladas com outros saberes que constituem os Projetos Pedagógicos em Psicologia.

PALAVRAS-CHAVE: Educação. Subjetividade. Ensino em Saúde. Formação do Psicólogo. Biopoder.

\begin{abstract}
We present the partial results of a research on the teaching of Psychopathology in Brazilian Psychology courses and, having as corpus 5 (five) discipline syllabus, one from each region of the country. Affiliated to the Foucaultian studies, the aim of this work consists in discussing the relations between modes of production of subjectivity, governmentality, biopolitics and discipline. The results point the teaching of Psychopathology as a device for (re)production of subjectivities linked to the mechanisms of control and administration of bodies and populations and indicate the necessity of reassessment of its place in relation to the new demands placed by the public policies, highlighting the Unified Health System. We understand that the object of study of the discipline, the discursive relations present in this field and the intervention techniques operate as the foundation of professional practices of significant ethical consequences to the Country and, therefore, require their own alterations and articulated with other knowledges that constitute the Pedagogical Projects in Psychology.
\end{abstract}

KEYWORDS: Education. Subjectivity. Health Teaching. Teaching of the Psychologist. Biopower.

\footnotetext{
${ }^{1}$ Doutor em Linguística Aplicada - Universidade Estadual de Campinas (UNICAMP) - Campinas, SP - Brasil. Docente - Universidade Federal da Grande Dourados (UFGD) - Dourados, MS - Brasil. E-mail: conradosathler@ufgd.edu.br.

${ }^{2}$ Doutora em Linguística Aplicada - Universidade Estadual de Campinas (UNICAMP) - Campinas, SP- Brasil. Docente - Universidade São Francisco (USF) - Itatiba, SP - Brasil. E-mail: marciaaam@uol.com.br.

Submetido em: 15/03/2018 - Aceito em: 26/10/2019
} 


\section{RESUMEN}

Presentamos los resultados parciales de una investigación sobre la enseñanza de Psicopatología en cursos brasileños de Psicología, teniendo como corpus 5 (cinco) menús, una de cada región del país. Filia a los estudios foucaultianos, el objetivo de este trabajo consiste en discutir las relaciones entre modos de producción de subjetividad, gubernamentalidad, biopolítica y disciplina. Los resultados apuntan la enseñanza de la Psicopatología como dispositivo de (re) producción de subjetividades en la Educación ligadas a los mecanismos de control y administración de cuerpos y poblaciones e indican la necesidad de reevaluación de su lugar frente a las nuevas demandas planteadas por las políticas públicas destacando el Sistema Único de salud. Comprendemos que el objeto de estudio de la disciplina, las relaciones discursivas presentes en este campo y las técnicas de intervención fundamentan acciones profesionales de consecuencias éticas significativas al país y, por ello, requieren alteraciones propias y articuladas con otros saberes que constituyen los Proyectos Pedagógicos en Psicología.

PALABRAS CLAVE: Educación. Subjetividad. Enseñanza en Salud. Formación del Psicólogo. Biopoder.

\section{INTRODUÇÃO}

O objetivo deste texto é apresentar uma análise de ementas da disciplina de Psicopatologia em cursos brasileiros de Psicologia. A abordagem adotada será a foucaultiana e para alcançar a finalidade a que nos propomos apresentaremos como preâmbulo alguns de seus conceitos centrais para o desenvolvimento de nossos argumentos analíticos: sujeito, disciplina, biopolítica e governamentalidade.

Este trabalho é parte de um projeto de pesquisa docente voltado ao estudo do ensino de Psicopatologia em cursos de graduação e pós-graduação, acompanhando os discursos circulantes na sala de aula, em busca da compreensão das implicações subjetivas, das concepções políticas do campo psicopatológico e da delimitação de seu objeto de estudo. Assim, vale ressaltar, a Psicopatologia se constitui como campo heterogêneo e as abordagens tratam de concepções de sujeito com variações históricas, no entanto, observa-se a valorização da visão organicista na formação e nos campos profissionais (MORAES; Macedo; 2018). O corpus é documental, acessado pela rede mundial de computadores e composto por dados oficiais de 5 Instituições de Ensino Superior (IES). Não as identificaremos para garantir o anonimato.

Nosso pressuposto teórico é que ao selecionar um objeto em um campo vasto, tenso e não consensual a Psicopatologia constrói descrições, relações e atributos que definem seu objeto de investigação e intervenção profissional e com isso institui também lugares sociais para seu sujeito, validando critérios de avaliação e de administração da população (SATHLER, 2008a; HACKING, 2004-2005). Nossa hipótese é que no ensino de Psicopatologia são articulados discursos biológicos, estatísticos, psicométricos e farmacológicos, entre outros, que possibilitam ao estudante projetar-se à posição de avaliador e classificador, assegurandoIhe um lugar de discriminação vinculado ao dispositivo da bioidentidade no governo dos corpos e das populações. Não pretendemos, portanto, discutir as relações entre as concepções teóricas, promover críticas direcionadas às práticas de ensino ou de métodos de investigação em Psicopatologia. A proposta foucaultiana, que nos dirige, é a de buscar

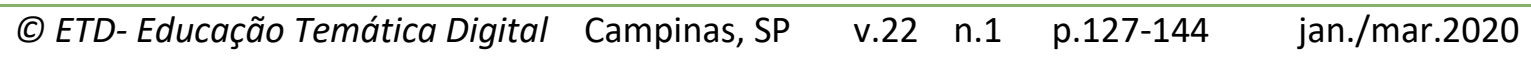


compreender os jogos de linguagem que permitem a emergência de vários discursos e como esses constituem-se, em um momento limitado, como o verdadeiro (FOUCAULT, 1996).

A disciplina de Psicopatologia é majoritariamente presente na matriz curricular de Psicologia e frequentemente está entre as disciplinas básicas da formação profissional como Psicologia do Desenvolvimento, Avaliação Psicológica e Teorias da Personalidade, o que confere um estatuto de fundamento indispensável, presumindo que sua falta comprometeria o desempenho nos campos de intervenção escolar, hospitalar, clínico ou jurídico. Essa concepção é herdeira de um currículo em modelo biomédico que associa a Psicopatologia à Avaliação Psicométrica e está ainda distante da pretendida para formar trabalhadores para o Sistema Único de Saúde (SUS) que opera sobre eixos voltados à Psicologia Social e Comunitária (GUARESCHI et al, 2009). Outros autores consideram que a Psicopatologia deve voltar-se às classificações taxonômicas e seria um saber essencial à Avaliação Psicológica (NUNES et al, 2012).

As consequências da instituição de um objeto psicopatológico, da apropriação dos discursos que o definem como científico e de sua valorização no ensino da profissão são as condutas às quais serão submetidos os sujeitos identificados como desviantes da norma produzida por esses discursos. A prática clínica, as políticas de Saúde Mental, os encaminhamentos escolares e as avaliações jurídicas, entre outros procedimentos profissionais, sustentam-se por essa competência profissional (GUARESCHI et al, 2011; GUARESCHI et al. 2009).

A Psicopatologia não é, evidentemente, isolada ou o centro da questão. Há uma composição discursiva e de condições sociais de produção que tornam as políticas de atuação profissional aceitas pela comunidade nacional. Nossa concepção de currículo, consiste em entender que [...] "o currículo é um campo em que estão em jogo múltiplos elementos, os quais estão implicados em relações de poder e compõem uma política cultural" (GUARESCHI et al., 2009, p. 37). Apresentaremos um pouco dessa formação profissional e das condições educacionais componentes desse quadro.

Em levantamento realizado no e-MEC, em 17 de janeiro de 2018, o Brasil contava com quase 800 cursos cadastrados de graduação em Psicologia. Apontaremos os números nos estados mais populosos: São Paulo, 174 cursos em andamento (44 na capital); Minas Gerais, 93; Rio de Janeiro e Bahia, 52 cada um. Paraná, 54 e Rio Grande do Sul, 60. Ceará e Pernambuco, 30 cada um. Somam-se 545 cursos, todos presenciais. Há muitos cursos no interior dos estados e a maioria tem avaliação média no Exame Nacional de Desempenho de Estudantes (ENADE). O número de vagas abertas por unidade de ensino varia de 100 a 700 vagas anuais. Esse número nas IES públicas e gratuitas é inferior ao de vagas das IES pagas, sejam elas públicas com cobrança de mensalidades, comunitárias, confessionais ou com fins lucrativos.

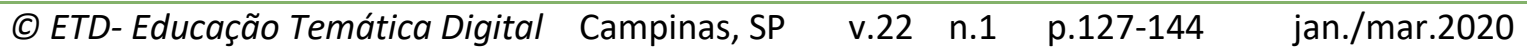


$\mathrm{O}$ alto número de vagas e o fato de as escolas formadoras trabalharem em busca de lucro auxiliam na compreensão do tipo de formação em marcha (MACEDO et al, 2017). Os cursos são montados visando a avaliação mínima para o funcionamento e as salas de aula são cheias de jovens capturados pelo desejo de reconhecimento e de alguma ascensão social. Esses fatores regidos pelo discurso neoliberal, que afirma ser o sucesso uma consequência do esforço individual, assegura grande contingente em busca de investimento em profissões cuja perspectiva inclua atuação autônoma. Esse é o cenário prevalente de nossa formação profissional em Psicologia: estudantes em escolas particulares com avaliação mediana e em regime parcial de estudo. A formação se conclui em 5 anos, raramente 4, e com carga horária entre 4.000 e 4500 horas. Dessas entre 60 e 150 horas são destinadas à Psicopatologia.

Entre as condições mais ou menos generalizadas de funcionamento das IES formadoras estão: pequeno investimento em pesquisa, esparsos programas de extensão universitária (tornando praticamente inexistente o contato com seus territórios, exceto pela oferta dos estágios obrigatórios), raras atividades de política acadêmica e de participação social refletindo as condições de funcionamento dos Órgãos de Controle Social do País e também os sintomas históricos de nossa cidadania.

A fragmentação do pensamento educacional tem se naturalizado e damos alguns esclarecimentos auxiliados por Guzzo (2007): além de exigir a pesquisa como uma tarefa universitária é preciso criar uma cultura de curiosidade e de problematização da realidade; traduzir a extensão como espaço de aplicação de conhecimentos é promover a soberba acadêmica (extensão é espaço privilegiado de escuta e de contato com uma realidade que coloca em xeque os saberes); o ensino não deve ser a prática de transmissão de um saber, mas integração das atividades de pesquisa, extensão, reflexão e políticas para a produção de uma sociedade mais justa.

Nessa direção, o movimento político estudantil é também fundamental, pois o estudante percebe sua realidade não como um espaço de passividade, mas sim de disputas onde todos são produtores e os embates e transformações podem partir de todos os pontos. Destacamos as lutas estudantis que ultrapassam a luta pela inclusão alcançando a garantia de condições igualitárias aos acadêmicos (PAULA, 2003).

Na carência das propostas da maioria dos cursos resta a sala de aula como espaço formador com métodos de ensino conservadores e professores contratados em regime horista, sem tempo de dedicação aos estudos ou às atividades administrativas e acadêmicas próprias da função. Com isso, as vinculações institucional e pedagógica tendem à míngua. Daí resulta um profissional formado para o passado e não para o futuro, com pouca capacidade de pensar e promover uma modificação da realidade vivida, sendo geralmente promotor dos discursos de adaptação e não de renovação ou transformação social (LISBOA; BARBOSA, 2009). Essa crítica já era produzida na década de 1980 pela Psicologia Social (LANE, 1991). A

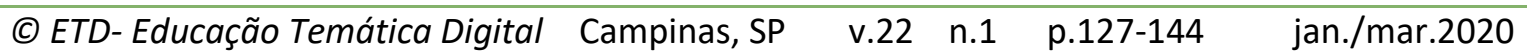


razão desse estatuto de maquinário formativo, do ponto de vista foucaultiano, é que uma escola não produz conhecimento, habilidades e competências, produz sim, subjetividades

\section{DISPOSITIVOS DA EDUCAÇÃO NA PRODUÇÃO DE SUJEITOS}

O tema dos estudos de Foucault sempre foi o sujeito e seu percurso deu-se pelos processos do saber, do poder e da ética (FOUCAULT, 1982; DREYFUS; RABINOW, 1995). A concepção desse campo torna impossível, no entanto, uma individualização desses conceitos, pois saber implica poder e ambos constituem uma ética. O que nos permite separá-los para efeito pedagógico, especialmente, é enfatizar os estudos da linguagem nas instituições e nos modos de objetivação do sujeito na relação consigo mesmo e com os outros nos processos de constituição de subjetividades.

Nosso trabalho atual é tentar rastrear na materialidade linguística das ementas de Psicopatologia como o sujeito da anormalidade é concebido. Observamos que esse sujeito foi presente em Foucault, em todas as fases de sua obra. Vejamos: A História da Loucura (1997 [1963]) tratou da produção social do louco, A Sociedade Punitiva (2015 [1973]) e Vigiar e Punir (1987 [1975]) trataram da construção social dos sujeitos perigosos e da prisão. Os Anormais (2001 [1975]) teve a temática dos sujeitos monstruosos, incorrigíveis e da criança masturbadora. Por fim, em a História da Sexualidade: a vontade de saber (1988 [1976]) o foco foi a hipótese repressiva no controle da sexualidade, o que toca a Psicanálise em sua ética. Essas obras indicam que seus métodos de análise variam. Mais apropriado seria afirmar que se constroem de acordo com o objetivo de cada investigação, logo, não há um conjunto de procedimentos pré-estabelecidos, anteriores ao corpus (FOUCAULT, 1977, p. 229). E, a esse propósito, podemos afirmar que um conjunto de conceitos será formulado na operacionalização das análises. Seus conceitos não são meras abstrações, são dispositivos palpáveis de análise.

Para manter uma coerência com a complexidade do pensamento foucaultiano, discutiremos alguns conceitos que auxiliam a compreensão da construção dos objetos de nossas ementas, entendendo que esse campo é atravessado, hoje, por epistemologias, disputas institucionais e outros discursos concorrentes na produção de sentidos que se sustentam socialmente, em nosso contexto, com sujeitos e objetos psicopatológicos dispostos na lógica neoliberal e de mercado. Ao afirmar que os conceitos são dispositivos de análise, não negamos a existência ou a essência constitucional de qualquer elemento, mas atrelamos os conceitos a uma linguagem que os definem e, ao defini-los, os inserem em um conjunto maior de definições e enquadres objetivos. É dessa concepção que deriva o conceito de sujeito. Não há um sujeito não dito e todo dizer é interpretação, cria efeitos de sentido e, por fim, torna-se parte do próprio interpretado. 
[...] se a interpretação nunca pode se concluir, é simplesmente porque nada há a interpretar. Nada há, absolutamente primeiro a interpretar, pois no fundo tudo já é interpretação; cada signo é nele mesmo não a coisa que se oferece à interpretação, mas interpretação de outros signos (FOUCAULT, 2005, p. 47)

Em termos Foucaultianos significa que uma teoria, uma episteme, uma prática que se repete, um saber ou uma crença, entre tantos outros poderes presentes no universo da linguagem, atribuem ao sujeito predicados que o delineiam, subordinam, localizam, categorizam, distribuem e destinam quando o descrevem. Dessa forma, o sujeito está assujeitado a esse conjunto de discursos e práticas. Isso não significa imobilidade. Pelo contrário, esses poderes são instáveis, ameaçados incessantemente e reagem, se transformam e escapam em jogos de capturas, fugas, camuflagens, metamorfoses, aderências e desbotamentos. Pelo que lutam? Pelo direito à palavra e pela constituição dos sentidos de cada signo.

Como essa dinâmica é inexaurível e fecunda não há um sujeito pronto. Há um processo de subjetivação, sempre em devir, embora inscrito em políticas de identidades que buscam capturar algo que destine o potencial assujeitado a conformar-se a algum interesse participante do jogo.

Para restringir a aleatoriedade foram desenvolvidas técnicas educativas ou, mais propriamente, administrativas dos corpos, dos coletivos e dos Estados. Essas técnicas são dispositivos articulados que agem no processo, na ação, direcionando-a. A disciplina é um tipo de dispositivo que atua sobre os corpos individuais. Um corpo disciplinado contém uma mente disciplinada. O interesse maior é a contenção, é tornar o indivíduo obediente, produtivo, dócil e previsível. Entre os mecanismos de ação da disciplina estão a fragmentação do corpo e do saber, a vigilância e o exame (FOUCAULT, 1999d).

O corpo disciplinado é treinado em habilidades específicas: movimentos, ritmos, posições. A essas habilidades somam-se justificativas lógicas que afirmam as vantagens da disciplina. O corpo treinado torna-se manufatura do efeito da vigilância e do exame. A vigilância, agora digital, constante e sem limites espaciais, conforme Deleuze (1992), dá a percepção de eficácia perene dessa atenção e, ao longo do processo, o vigiado introjeta a vigilância e torna-se seu próprio vigia e ainda há exames objetivando medir seu desempenho. Com isso há uma objetivação: criam-se parâmetros que produzem classificação e distribuição de frequência de atos, gestos, padrões, classes, médias, tendências coletivas... (SATHLER, 2016).

A estatística é a ciência do Estado. A administração dos corpos se faz pela via disciplinar e o conjunto de corpos disciplinados é dirigido pela biopolítica. O dispositivo da biopolítica trata não somente de como o coletivo deve conduzir-se, trata também de quem deve viver e a quem o Estado deixa morrer (FOUCAULT, 2008). Mecanismos políticos como a 
vacinação elegem segmentos sociais prioritários, indicam doenças de notificação compulsória, as combatem seletivamente e protegem determinados trabalhadores. As regras para o governo da vida são tecnologias difundidas.

A transformação das experiências essenciais da vida subjetiva numa série de intervenções que ameaçam a saúde do homem retira do sofrimento seu significado íntimo e pessoal e transforma a dor em um problema técnico. A submissão à regulação faz com que a população recorra sem cessar a consumos (de medicamentos, hospitais, serviços de saúde mental etc.) cuja produção é monopolizada pela instituição médica. Esses são alguns dos sintomas da iatrogênese biomédica que começam a se impor com a expansão do saber médico na sociedade ocidental (MARTINS, 2008, p. 333).

O império que se fundava no séc. XVII sobre o poder soberano, sobre o arbítrio da morte vergonhosa, se desloca para a produção da vida. Porém, o fazer viver não é livre de controles, é uma produção seleta e dirigida para um tipo específico de vida.

O controle da sociedade sobre os indivíduos não se opera simplesmente pela consciência ou pela ideologia, mas começa no corpo, com o corpo. Foi no biológico, no somático, no corporal que, antes de tudo, investiu a sociedade capitalista. 0 corpo é uma realidade bio-política. A medicina é uma estratégia bio-política (FOUCAULT, 1999a, p. 80).

Nessa transição dos processos de gestão da população, a Medicina apropriou-se do corpo como seu objeto e o associou às produções dos comportamentos. A Psiquiatria, então, investiu em um discurso que, ao separar a doença orgânica do que era da esfera moral, construiu estratégias de criação de um saber científico aceitável de inserção da loucura na instituição médica. Essa separação não se encerrava quando discriminava, pois continuava investigando os processos mentais na busca de substratos biológicos, bioquímicos ou neuroquímicos para dar credibilidade aos procedimentos descritivos, classificatórios, terapêuticos ou administrativos.

A produção desencadeada por esse processo contém o que Rose (2008) chamou de Self Psicológico e a organização desses conhecimentos se deu em dupla partida: a primeira com descrição, classificação, administração e distribuição dos comportamentos anormais e a segunda com acumulação de saberes institucionais por meio da observação de condutas nas escolas, prisões, fábricas, tribunais etc. Dito de outra forma, a Psicopatologia se insere institucionalmente nos jogos da administração pública criando, por meio da normalização, a normatização dos comportamentos.

O governo se transforma, passa do modelo familiar do Estado soberano para o modelo administrativo, uma arte de governar na qual há um forte imbricamento da economia com os rumos da população. $O$ governante aceito nesse regime não é mais aquele senhor poderoso, ao contrário, é aquele que age como se buscasse apenas atender as demandas populares e dessa forma cumprir a missão do Estado (FOUCAULT, 1999c. Assim, um conjunto complexo 
de elementos se localiza nesse modelo chamado governamentalidade. Apontamos como imprescindíveis a essa arte de governar a presença de um conhecimento específico sobre a população. Conhecer hábitos, desejos, padrões de consumo, mentalidades e práticas implica em (re)conhecer as instituições que capturam esses sujeitos e fazer incidir sobre os desejos um plano que garanta a sensação de bem-estar, saúde, progresso, segurança, autonomia e liberdade.

A linguagem que liga o sujeito a si mesmo nesse contexto é a linguagem "Psi". A manifestação do mal-estar e do bem-estar, a elaboração do desejo, a identificação dos desvios e a nomeação das sensações de si estão postas em expressões psicológicas. Da mesma forma, a relação com os objetos, com o tempo, com o espaço e com o próprio corpo é marcada por essa linguagem que encaminha todos à instituição "Psi", aos seus analistas, terapeutas e conselheiros.

A governamentalidade se instaura pelas associações dos desempenhos, desejos, estados mentais e habilidades pontuados desde os primeiros momentos da vida. A resposta materna primária, a vinculação precoce, o desenvolvimento guiado pelas tarefas desenvolvimentais, a inteligência emocional, a automotivação, o quociente intelectual, o complexo de Édipo, a moratória adolescencial e a resiliência são exemplos desta farta linguagem e esses construtos se tornam parâmetros individuais e categorias de classificação social em todos seus segmentos.

Para encerrar este preâmbulo, retomaremos o conceito de sujeito. Há uma tendência ao pessimismo pelo impacto a esse tipo de concepção de relações de poder. Numa crítica autodirigida, percebemos que o léxico sujeito, derivado do assujeitado, dá a impressão de aprisionado. Chamamos a atenção para a importância da resistência como proposta por Foucault (1999b, p.191), cuja expressão mais repetida é: onde há poder, há resistência. No entanto, esse é um raciocínio binário e tributário da memória linguística da terceira lei de Newton expressa na fórmula: a toda ação corresponde uma reação de igual intensidade, mas que atua em sentido oposto. Poder e resistência em Foucault não são duas substâncias materiais ou imateriais que se complementam. Onde há poder, há a possibilidade de resistência e as condições de emergência de um poder coexistem com as manifestações da resistência.

Ainda na direção da concepção de sujeito, compreendemos haver em todo lugar um conjunto de atravessamentos discursivos, normas, práticas e condições de existência. Frente a isso, o sujeito jamais é neutro, passivo ou laboratorialmente posto sobre a força de vetores. Assim, ao ser atravessado por dizeres e poderes, ideologias e desejos, há uma deformação provocada pela resistência que, acima de tudo, mantém singularidades tantas vezes inalcançáveis, só tocadas pelos rastros passageiros de faíscas ejetadas da violência dos embates discursivos (FOUCAULT, 1996).

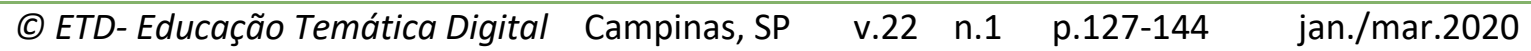


Organizamos a análise por eixos, buscando a localização de temas de forte significação para nossa investigação e verificamos enunciados ou palavras que orbitam o tema e produzem coletivamente um sentido possível. Como dissemos, fragmentamos as ementas e nesse relato destacamos em itálico o que selecionamos.

\section{A PSICOPATOLOGIA NAS EMENTAS}

As ementas são resumos de conteúdos descritos em frases nominais. São células que delimitam um plano de curso e, associando-se a outras, resultam uma matriz curricular. Por ser celular apresenta clara limitação e indica especificidade disciplinar. Logo, consideramos encontrar na ementa ligações a outras disciplinas, sugerindo especificidade. Organizamos essa análise em eixos relativos: a) à delimitação do objeto de estudo, exposto no subitem "Que objeto é este?", b) à heterogeneidade discursiva, tomada por breve análise semântica desse objeto, descrita no subitem "Tramas discursivas do objeto da Psicopatologia" e c) às propostas que apontam para uma pragmática disciplinar abordada com o subtítulo "Produção de conhecimento e técnicas 'Psi' de controle". Os excertos das ementas estão em itálico.

\subsection{Que objeto é este?}

Uma leitura atenta nos despertou o interesse pela compreensão de qual objeto é concebido pelas ementas. Encontramos algumas pistas sobre a natureza desse objeto. Podemos notar em enunciados como História crítica do conceito de doença mental: normal e patológico; Psicopatologia: história, definições, modelos e abordagens; e Aspectos históricoconceituais da psicopatologia; Evolução do conceito de psicopatologia: critérios de saúde e doença mental [.] uma centralidade da história conceitual. Isso pode indicar que tanto a construção do objeto quanto a sua compreensão teórica é delineada por contextos. Poderíamos dizer que, por esse viés, a Psicopatologia não estuda nem se apropria de uma essência ou de um dado externo, independente e invariável, mas de um objeto próprio de uma construção historicamente determinada e, portanto, variável e não portadora de uma essência.

Essa concepção difere das afirmações mais descritivas, categoriais e voltadas às concepções positivistas e fenomenológicas. Assim, ao apontar o estudo da História da psicopatologia científica ou da [...] psicopatologia estruturante da personalidade ou ainda do fenômeno psicopatológico, as ementas identificam um objeto mais concreto, localizável e isolável. Apontamos, principalmente, na proposta do estudo de uma psicopatologia estruturante da personalidade, resquícios de uma clínica tradicional, estruturalista, que representa uma oposição ao pensamento de base Biopsicossocial, em consonância com Ribeiro e Luzio (2008) e Carneiro e Porto (2014). 
Contudo, nessa pequena amostra, a noção de doença pode ser tocada, mais evidentemente, nas expressões doença mental, nosografia psiquiátrica, síndromes, entidades nosológicas e sintomas, outras vezes surge como um lapso materializado nos léxicos: pacientes, a complicação do fenômeno psicológico ou o papel do psicólogo na instituição hospitalar. Observamos variação nos enunciados postos em contextos sociais diferentes e por isso com efeitos de sentido diferentes, mas glosamos - doença mental é algo do sujeito doente e nosografia psiquiátrica carrega a marca do relato da doença (nosografia) e da especialidade médica (psiquiátrica). A síndrome é um conjunto de sintomas associados a processos patológicos que em configuração específica forma um quadro diagnóstico e o sintoma é um sinal de alteração orgânica. Destacamos ainda nesse grupo os sintagmas instituição hospitalar e paciente que não carregam diretamente a doença em seu léxico, mas, o sujeito da instituição hospitalar ou paciente, representam doentes. Logo, ontológica ou epistemologicamente, estamos tratando da Psicopatologia já apropriada por discurso biomédico e não por sofrimento, paixão, exclusão social ou subordinação hierárquica.

Há, nesse ponto, a possibilidade de perceber o que Hacking (2002) aponta há mais de uma década no sentido da naturalização da dobra, dispositivo do sujeito psíquico. Em termos práticos, observamos os efeitos da linguagem "Psi" na designação técnica de anamnese $e$ súmula psicopatológica, ou seja, na possibilidade técnica de uma "narrativa do eu" que é sustentada por um discurso diagnóstico. Nessa prática, ouvir o outro se transforma automaticamente em escuta clínica e o profissional vai se apropriando do outro pelo discurso da autoridade sobre o corpo e sobre as ameaças da complicação do fenômeno psicológico que pode, enfim, acolher e encaminhar a destinos bem marcados: Avaliação e Psicodiagnóstico, Promoção e prevenção da saúde mental, Práticas psicológicas em contextos institucionais e Intervenções clínicas.

\subsection{Tramas discursivas do objeto da Psicopatologia}

Sem pretender rastrear os sentidos provocados no uso de palavras marcadas pelas abordagens teóricas e paradigmas aos quais se associam, vamos apenas apontar algumas destas ligações de forma mais imediata. O recorte selecionado da primeira ementa da amostra é História crítica do conceito de doença mental: normal e patológico. Da segunda ementa, recortamos Análise crítica de concepções fundamentais: Loucura, doença mental, normal e patológico, da terceira, Aspectos éticos relevantes em contextos institucionais e da quarta história da psicopatologia científica.

Esse conjunto de pequenos enunciados se agrupa por conter em si uma separação de discursos psicopatológicos. A história crítica pressupõe a história da naturalização acrítica do objeto conceito de doença mental e ainda na sequência normal e patológico, indicando que todos esses conceitos devem passar por um crivo que minimamente surpreenda em caso de

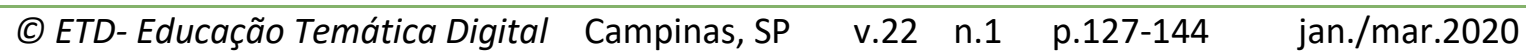


leitura ingênua. A mesma função emerge na segunda ementa ao enunciar Análise crítica de concepções fundamentais, o que aponta para a problematização do considerado fundamental. O enunciado aspectos éticos relevantes é, hoje, polissêmico. Sem discutir a concepção de ética, apontamos que as instituições em suas práticas constroem éticas que precisam ser discutidas ou, melhor dizendo, cada contexto institucional traz aos seus sujeitos consequências éticas. Por fim, a história da psicopatologia científica, novamente desconsiderando os conflitos sobre as concepções de história, indica a existência de uma psicopatologia não científica da qual a psicopatologia científica precisa diferenciar-se.

O que abstraímos desse pequeno conjunto de enunciados é que não se constrói uma concepção de Psicopatologia sem antes desestabilizar os conhecimentos do senso comum levados ao contexto escolar. Assim, uma tarefa do moderador da classe é provocar deslocamentos dos saberes circulantes em meios acadêmicos e profissionais para um pensamento menos ingênuo e compromissado com uma Ética. O saber em Psicopatologia é, desta forma, uma leitura do momento social, como apontado em estudos realizados por Han (2017) e pelo Sathler e Rezende (2008b) e uma construção política, como apontado por Pizzinga e Vasques (2018) e Sales e Dimenstein (2009).

\subsection{Produção de conhecimento e técnicas "Psi" de controle}

Apontaremos mais uma regularidade discursiva, entre tantas possíveis, agora localizada ao final das ementas. Os excertos são: Avaliação e Psicodiagnóstico. Promoção e prevenção da saúde mental, Intervenções clínicas [...]: plantão psicológico, grupos de espera, terapias breves, anamnese e súmula psicopatológica, exame das funções psíquicas, sinais, sintomas e síndromes, e 0 papel do psicólogo na instituição hospitalar e em equipes multidisciplinares. Vamos nos ater aos aspectos centrados no poder interventivo que o lugar ocupado por este saber implica, porém há regularidades a serem analisadas em outro momento, tais como: disciplinaridade, institucionalização social, campos de trabalho projetados e linguagem técnica.

Examinar, avaliar, promover e intervir são verbos dos excertos e mostram ações que atingem objetos. Exame, avaliação, anamnese, súmula, teorias e técnicas clínicas são conteúdos de outras disciplinas. A Psicopatologia funciona como síntese para validação conceitual dos saberes das disciplinas de Desenvolvimento, Estatística, Medidas Psicométricas, Neuropsicologia, Psicofarmacologia e Políticas Públicas, segundo Guareschi et al. (2009) e Nunes et al. (2012). As ementas organizam, ao final, encaminhamentos possíveis a cada ação implícita ao ato de descrever, nomear, quantificar e classificar condutas por uma norma validada. O conhecimento da linguagem classificatória, dos mecanismos de observação e disposição em categorias dá ao avaliador um lugar de poder, apesar de as normas serem majoritariamente disciplinares e morais, como consta em nossa hipótese. 
Esse poder está suficientemente institucionalizado para o exercício do enquadre dos sujeitos em categorias. Assim, os encaminhamentos observados têm consequências ligadas aos Aspectos éticos relevantes em contextos institucionais e são atribuições inquestionáveis. O papel do profissional é encaminhar disciplinar, jurídico ou administrativamente para intervenções clínicas, hospitalares, escolares, jurídicas etc. Esse poder endossa as posturas de psicologização, psiquiatrização e medicalização social, tal qual observado por Gomes e Pedrero (2015); Firbida e Vasconcelos (2019); e Moraes e Macedo (2018).

A apropriação de um saber psicopatológico é, portanto, a produção de uma subjetividade voltada à normatização dos comportamentos, um dispositivo de classificação que parte do corpo do sujeito avaliado para produzir, em uma aplicação direta, a normalização de biotipos promotora de bioidentidades marcadas pela força da biopsiquiatrização, argumento final do controle dos sujeitos sociais.

\section{CONSIDERAÇÕES FINAIS}

Essa investigação permitiu alguns destaques nos eixos discursivos sobre o objeto de estudo da Psicopatologia, as tramas que o envolvem e a produção de conhecimentos e técnicas de controle pela via dos discursos e práticas circulantes nesse campo.

O primeiro eixo, objeto conceitual da Psicopatologia, é apresentado nas ementas como uma construção historicamente modelada e, possivelmente, devido às condições atuais de produção de discursos educacionais, se configura majoritariamente como efeito do Biopoder ou como um objeto naturalizado nos discursos "Psi" de composição biomédica. Com o deslocamento das DCN (2004) do modelo biomédico para o atendimento às Políticas de Saúde organizadas pelo SUS, o ensino de Psicopatologia revela, pelas suas ementas, resistências à atualização e às dificuldades de abandono da centralidade da clínica na formação profissional e dificuldades de desenvolvimento de competências para a atuação social preventiva e educativa. Essas resistências são semelhantes às considerações que Ribeiro e Luzio (2008) e Carneiro e Porto (2014) apontam em suas análises sobre os PP dos cursos de Psicologia.

O segundo eixo aponta a necessidade de (re)construção do objeto presente em sala de aula. Como o sujeito contemporâneo se define pela linguagem "Psi", os estudantes têm a expectativa de fundamentar em classe o que circula socialmente sobre o tema, transformando o saber leigo em científico. Isso pode ou não ser feito, no entanto, dessa (re)construção e validação de conhecimentos resulta uma ética para os tratamentos e encaminhamentos institucionais do sujeito psicopatológico. Os estudos de Han (2017), Pizzinga e Vasques (2018) e Sales e Dimenstein (2009), com quem concordamos, mostram a necessidade da reavaliação do lugar da Psicopatologia como leitura dos modos de expressão do sofrimento do sujeito contemporâneo e também de uma reflexão de seu papel como

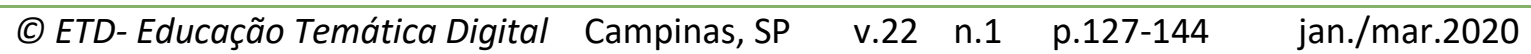


participante dos movimentos sociais de medicalização, psicologização e psiquiatrização dessas expressões.

O terceiro eixo indica que nossa hipótese é plausível, ou seja, que a disciplina busca compor com outros saberes da matriz curricular relativos ao Desenvolvimento, à Avaliação e às Políticas Públicas, a subjetividade de um avaliador que, além do domínio de uma técnica aceita de avaliação, domina também seus critérios. Esses domínios coincidem com a governamentalidade sendo, dessa forma, validados pela ciência política de governo atual.

Por fim, o funcionamento de grande parte das IES formadoras de Psicólogos contribui para esse modelo de formação de subjetividade que integra o dispositivo de Educação que, ao cabo, é um dispositivo de controle e administração dos corpos e das populações. Isso pode confirmar o que vem sendo denunciado pela Psicologia Social desde a década de 1980 (LANE, 1991) e reafirmar o que foi visto por Lisboa e Barbosa (2009), sem alteração: a formação profissional em Psicologia se faz para o passado e não para o futuro e a disciplina de Psicopatologia é componente desse cenário conservador.

Observamos, assim, que uma mudança é necessária nesse cenário, porém, embora a alteração em Psicopatologia seja requerida, não é suficiente. Devem ocorrer novas pesquisas curriculares e relações disciplinares, como apontam Moraes e Macedo (2019). E também inovações nos PP que considerem pesquisa, extensão, ensino e movimentos estudantis como atravessamentos indispensáveis a uma formação profissional em Psicologia que atenda às demandas atuais da sociedade brasileira.

\section{REFERÊNCIAS}

BERNARDES, Jefferson de Souza. A formação em psicologia após 50 anos do Primeiro Currículo Nacional da Psicologia: alguns desafios atuais. Psicol. cienc. prof., Brasília, v. 32, n. spe, p. 216231, 2012. Disponível em: http://www.scielo.br/scielo.php?script=sci arttext\&pid=S141498932012000500016\&lng=pt\&nrm=iso. Acesso em: 17 jun. 2019.

CARNEIRO, Larissa; PORTO, Celmo Celeno. Saúde Mental nos cursos de graduação: interfaces com Diretrizes Curriculares Nacionais e com a Reforma Psiquiátrica. Cadernos Brasileiros de Saúde Mental. v. 6; n. 14, p. 150-167, dez. 2014. Disponível em: http://incubadora.periodicos.ufsc.br/index.php/cbsm/article/view/1666/3944 . Acesso em: 17 jun. 2019.

DELEUZE, Gilles. Post-scriptum sobre as sociedades de Controle. Conversações. 1972-1990. Rio de Janeiro: 34, 1992. p. 219 - 226. ISBN: 8585490047. Disponível em: http://netart.incubadora.fapesp.br/portal/midias/controle.pdf . Acesso em 30 set. 2005.

DREYFUS, Hubert L.; RABINOW, Paul. Michel Foucault, uma trajetória filosófica: para além do estruturalismo e da hermenêutica. Rio de Janeiro: Forense Universitária, 1995. 380 p. ISBN: 852180475X.

(C) ETD-Educação Temática Digital Campinas, SP $\quad$ v.22 $\quad$ n.1 $\quad$ p.127-144 jan./mar.2020


FIRBIDA, Fabíola Batista Gomes; VASCONCELOS, Mário Sérgio. A construção do conhecimento na Psicologia: a legitimação da medicalização. Psicol. Esc. Educ., Maringá, v.23, e016120, 2019. Disponível em: http://www.scielo.br/scielo.php?script=sci arttext\&pid=S14135572019000100304\&lng=pt\&nrm=iso Acesso em: 21 jun. 2019. Epub 03-Jun-2019.

FOUCAULT, Michel. História da loucura na idade clássica. 5. ed. São Paulo: Perspectiva, 1997. 555 p. [Original de 1963]. ISBN: 8527301091

FOUCAULT, Michel. A sociedade punitiva. São Paulo: WMF Martins Fontes, 2015. 323 p. [Curso no Collège de France de 1972-1973]. ISBN: 8546900108

FOUCAULT, Michel. Os anormais. São Paulo: Martins Fontes, 2001. 580 p. [Curso no Collège de France de 1974-1975]. ISBN: 8578273362

FOUCAULT, Michel. Vigiar e punir: o nascimento da prisão. 24. ed. Petrópolis: Vozes, 1987. 288 p. [Original de 1975]. ISBN: 8578273362

FOUCAULT, Michel. História da sexualidade I: a vontade de saber. 15. ed. Rio de Janeiro: Graal. 1988. [Original de 1976]. 246 p. ISBN: 8577532941

FOUCAULT, Michel. Poder e Saber (1977). Ditos e escritos IV: estratégia, poder-saber. Rio de Janeiro: Forense Universitária, 2014. P.223 - 240. ISBN: 8521804873

FOUCAULT, Michel. A ordem do discurso: aula inaugural no Collège de France em 02 de dezembro de 1970. 6. ed. Rio de Janeiro: Loyola, 1996. 79 p. ISBN: 85-15-01359-2

FOUCAULT, Michel. O nascimento da medicina social. In: MACHADO, Roberto (Org.), Microfísica do poder. 16. ed. Rio de Janeiro: Graal, 1999a. p. 79-98. ISBN: 8570380747

FOUCAULT, Michel. Não ao sexo rei. In: MACHADO, Roberto (Org.), Microfísica do poder. 16. ed. Rio de Janeiro: Graal, 1999b. p.229-242. ISBN: 8570380747

FOUCAULT, Michel. Governamentalidade. In: MACHADO, Roberto (Org.), Microfísica do poder. 16. ed. Rio de Janeiro: Graal, 1999c. p. 407-431. ISBN: 8570380747

FOUCAULT, Michel. A verdade e as formas jurídicas. 6. ed. Rio de Janeiro: Nau, 1999d. ISBN: 8585936266

FOUCAULT, Michel. Nietzsche, Freud, Marx (1977). Ditos e escritos II: arqueologia das ciências e história dos sistemas de pensamento. 2. ed. Rio de Janeiro: Forense Universitária, 2005. p. 40-55. ISBN: 8521804857

FOUCAULT, Michel. Segurança, território, população. São Paulo: Martins Fontes, 2008. 572 p. [Curso no Collège de France de 1977-1978]. ISBN: 8533623771

FOUCAULT, Michel. O sujeito e o poder (1982). Ditos e escritos IX: genealogia da ética, subjetividade e sexualidade. Rio de Janeiro: Forense Universitária, 2014. p.118-140. ISBN: $853093749 x$ 
GOMES, Cláudia Aparecida Valderramas; PEDRERO, Jennifer do Nascimento. Queixa escolar: encaminhamentos e atuação profissional em um município do interior paulista. Psicol. cienc. prof., Brasília, v. 35, n. 4, p. 1239-1256, dez. 2015. Disponível em:

http://www.scielo.br/scielo.php?script=sci arttext\&pid=S14148932015000401239\&lng=pt\&nrm=iso . Acesso em: 21 jun. 2019.

GUARESCHI, Neuza Maria de Fátima et al. A avaliação psicológica, psicopatologia e as psicoterapias na formação do profissional de saúde para o SUS: um estudo dos currículos dos cursos de Psicologia. Rev. Mal-Estar Subj., Fortaleza, v. 11, n.1, p. 171-204, mar. 2011. Disponível em: http://pepsic.bvsalud.org/scielo.php?script=sci arttext\&pid=S1518-

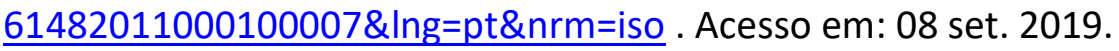

GUARESCHI, Neuza Maria de Fátima et al. A formação em Psicologia e o profissional da Saúde para o SUS (Sistema Único de Saúde). Arq. bras. psicol., Rio de Janeiro, v. 61, n. 3, p. 35-45, dez. 2009. Disponível em:

http://pepsic.bvsalud.org/scielo.php?script=sci arttext\&pid=S180952672009000300005\&lng=pt\&nrm=iso . Acesso em: 20 jun. 2019.

GUZZO, Raquel Souza Lobo. Reforma universitária, universidade nova e o futuro da psicologia. In: ENCONTRO NACIONAL DA ASSOCIAÇÃO BRASILEIRA DE PSICOLOGIASOCIAL (ABRAPSO), 14., 2007, Rio de Janeiro. Anais do ... Disponível em:

http://www.abepsi.org.br/wp-content/uploads/2011/07/ Artigo-Raquel-Guzzo1.pdf. Acesso em: 05 de janeiro de 2018.

HACKING, Ian. Façonner les gens. Philosophie et histoire des concepts scientifiques. Cours au Collège de France [2001-2002]. Disponível em: https://www.college-defrance.fr/media/professeurs-honoraires/UPL46353 UPL35833 hackingres0405.pdf Acesso em: 31 jan. 2018.

HACKING, Ian. Façonner les gens II. Philosophie et histoire des concepts scientifiques. Cours au Collège de France [2004-2005]. Disponível em: https://www.college-defrance.fr/site/ian-hacking/course-2004-2005.htm. Acesso em: 20 jun. 2019.

HAN, Buyng-Chul. Sociedade do cansaço. 2.ed. Petrópolis, RJ: Vozes, 2017. ISBN: 8532649963

LANE, S. T. M. Psicologia social e uma nova concepção do homem para a Psicologia. In: LANE, S. T. M; CODO, W. (Org.). Psicologia social: o homem em movimento. 9. ed. São Paulo: Brasiliense, 1991. ISBN: 8511150234

LISBOA, Felipe Stephan; BARBOSA, Altemir José Gonçalves. Formação em Psicologia no Brasil: um perfil dos cursos de graduação. Psicol. cienc. prof., Brasília, v. 29, n. 4, p. 718-737, 2009. Disponível em: http://www.scielo.br/scielo.php?script=sci arttext\&pid=S141498932009000400006\&lng=pt\&nrm=iso . Acesso em: 26 jan. 2018.

MACEDO, Joao Paulo et al. Transnacionalização do Ensino Superior: Impactos nos Processos Formativos em Psicologia no Brasil. Psicol. cienc. prof., Brasília, v. 37, n. 4, p. 852-868, dez. 
2017. Disponível em: http://www.scielo.br/scielo.php?script=sci arttext\&pid=S141498932017000400852\&lng=pt\&nrm=iso . Acesso em: 26 jan. 2018.

MARTINS, Anderson Luiz Barbosa. Biopsiquiatria e Bioidentidade: política da subjetividade contemporânea. Psicol. Soc., Florianópolis, v. 20, n. 3, p. 331-339, Dec. 2008. Disponível em: http://www.scielo.br/scielo.php?script=sci arttext\&pid=S010271822008000300003\&lng=en\&nrm=iso . Acesso em: 28 Jan. 2018.

MORAES, Fernanda Cesar Ferreira da Silva; MACEDO, Mônica Medeiros Kother A noção de Psicopatologia: desdobramentos em um campo de heterogeneidades. Ágora (Rio J.), Rio de Janeiro, v. 21, n. 1, p. 83-93, abr. 2018. Disponível em:

http://www.scielo.br/scielo.php?script=sci arttext\&pid=S151614982018000100083\&lng=pt\&nrm=iso . Acesso em: 21 jun. 2019.

NUNES, Maiana Farias Oliveira et al. Diretrizes para o ensino de avaliação psicológica. Aval. psicol., Itatiba, v. 11, n. 2, p. 309-316, ago. 2012. Disponível em: http://pepsic.bvsalud.org/scielo.php?script=sci arttext\&pid=S167704712012000200016\&lng=pt\&nrm=iso. Acesso em: 17 jun. 2019.

PAULA, Lucília Augusta Lino de. Protagonismo juvenil e movimento estudantil: uma estratégia de distinção? In: REUNIÃO ANUAL DA ANPED, 26., Poços de Caldas, 2003. Anais do... Disponível em: 26reuniao.anped.org.br/trabalhos/luciliaaugustalinodepaula.rtf. Acesso em 20 jun. 2019.

PIZZINGA, Vivian Heringer; VASQUEZ, Henrique Romero. Reificação, inteligência e medicalização: formas históricas e atuais de classificação na escola. Psicol. Esc. Educ., Maringá, v. 22, n. 1, p. 123-131, abr. 2018. Disponível em:

http://www.scielo.br/scielo.php?script=sci arttext\&pid=S141385572018000100123\&lng=pt\&nrm=iso . Acesso em: 21 jun. 2019.

RIBEIRO, Sérgio Luiz; LUZIO, Cristina Amélia. As diretrizes curriculares e a formação do psicólogo para a saúde mental. Psicol. rev. (Belo Horizonte), Belo Horizonte, v. 14, n. 2, p. 203-220, dez. 2008. Disponível em:

http://pepsic.bvsalud.org/scielo.php?script=sci arttext\&pid=S1677$11682008000200013 \&$ Ing=pt\&nrm=iso . Acesso em: 26 jun. 2019.

ROSE, Nikolas. Psicologia como uma ciência social. Psicol. Soc., Porto Alegre, v. 20, n. 2, p. 155-164, ago. 2008. Disponível em:

http://www.scielo.br/scielo.php?script=sci arttext\&pid=S010271822008000200002\&lng=pt\&nrm=iso . Acesso em: 29 jan. 2018.

SALES, André Luis Leite de Figueiredo; DIMENSTEIN, Magda. Psicólogos no processo de reforma psiquiátrica: práticas em desconstrução?. Psicol. estud., Maringá, v. 14, n. 2, p. 277285, jun. 2009. Disponível em:

http://www.scielo.br/scielo.php?script=sci arttext\&pid=S141373722009000200008\&lng=pt\&nrm=iso . Acesso em: 21 jun. 2019. 
ATHLER, Conrado Neves. Formações subjetivas: o sujeito à luz da teoria dos discursos. Dourados, MS: UFGD, 2016. 126p. ISBN: 978-85-8147-115-0

SATHLER, Conrado Neves. Escrita disciplinar e psicologia: laudos como estratégia de controle das populações. Campinas, SP: UNICAMP, 2008. 233 P. Tese (Doutorado em Linguística Aplicada) - Instituto de Estudos da Linguagem, Universidade Estadual de Campinas, Campinas, 2008a. Disponível em: http://repositorio.unicamp.br/bitstream/REPOSIP/269481/1/Sathler ConradoNeves D.pdf Acesso em: 30.09.2019

SATHLER, Conrado Neves; REZENDE, Manuel Morgado. Psicopatologia: legitimação de discursos pós-modernos na sala de aula. Rev. Mal-Estar Subj., Fortaleza, v. 8, n. 4, p. 10771098, dez. 2008b. Disponível em:

http://pepsic.bvsalud.org/scielo.php?script=sci arttext\&pid=S151861482008000400010\&lng=pt\&nrm=iso . Acesso em: 30 set. 2019.

SEIXAS, Pablo Sousa et al. As políticas sociais nos fundamentos dos projetos pedagógicos dos cursos de Psicologia. Psicol. Esc. Educ., Maringá, v. 20, n. 3, p. 437-446, dez. 2016. Disponível em: http://www.scielo.br/scielo.php?script=sci arttext\&pid=S1413$85572016000300437 \&$ lng=pt\&nrm=iso . Acesso em: 17 jun. 2019.

VILHENA, Junia de; ROSA, Carlos Mendes. Diagnóstico em saúde mental: por uma concepção não objetivista das representações da loucura. Contextos Clínic, São Leopoldo, v. 5, n. 1, p. 26-36, jul. 2012. Disponível em:

http://pepsic.bvsalud.org/scielo.php?script=sci arttext\&pid=S198334822012000100004\&lng=pt\&nrm=iso . Acesso em: 08 set. 2019.

\section{Revisão gramatical realizada por:}

Nilzira Aparecida Nabuco

E-mail: nilzira@gmail.com. 